\title{
Antimicrobial Activity of Polyhexamethylene Guanidine Derivatives Introduced into Polycaprolactone
}

\author{
Maria Swiontek Brzezinska ${ }^{1}$ - Maciej Walczak ${ }^{1} \cdot$ Urszula Jankiewicz $^{2}$ • \\ Marcela Pejchalová ${ }^{3}$
}

Published online: 28 February 2017

(C) The Author(s) 2017. This article is published with open access at Springerlink.com

\begin{abstract}
The research was aimed at determining the abundance of biofilm formation by Escherichia coli and Staphylococcus aureus on the surface of polycaprolactone (PCL) with polyhexamethylene guanidine (PHMG) derivatives and effect of the derivatives on extracellular hydrolytic enzymes and intracellular dehydrogenases. Biofilm abundance was determined by spectrophotometry, using crystal violet staining. Hydrolytic enzymes after contact with the film were determined with the use of non-specific substrate-fluorscein diacetate. The effect of PHMG derivatives on dehydrogenases activity was assessed using the test, where triphenyltetrazolium chloride (TTC) is reduced to triphenylformazan (TF). The PCL containing PHMG granular polyethylene wax and salt of sulfanilic acid (0.6$1 \%$ wt.) strongest inhibited biofilm formation. PHMG derivatives introduced into PCL were found to slightly affect hydrolases activity in both $E$. coli and $S$. aureus at a concentration of 0.2 and $0.6 \%$. It was also found that dehydrogenases activity was inhibited by PCL films containing PHMG derivatives. PCL containing $1 \%$ of PHMG sulfanilate strongest inhibited hydrolases activity, whereas PCL modified with $1 \%$ of PHMG granular polyethylene wax
\end{abstract}

Maria Swiontek Brzezinska

swiontek@umk.pl

1 Department of Environmental Microbiology and Biotechnology, Faculty Biology and Environmental Protection, Nicolaus Copernicus University, Lwowska 1, Torun 87-100, Poland

2 Department of Biochemistry, Warsaw University of Life Sciences, SGGW, Nowoursynowska 159, Warsaw 02-776, Poland

3 Department of Biological and Biochemical Sciences, Faculty of Chemical Technology, University of Pardubice, Studentská 573, 53210 Pardubice, Czech Republic showed the highest inhibitory effect on the activity of both enzymes. W-PCL and A-PCL composites (at concentration of $0.6 \%$ ) have optimal combination of antibiofilm activity and biodegradability.

Keywords Polycaprolactone - PHMG derivatives . Hydrolases · Dehydrogenases

\section{Introduction}

Polycaprolactone belongs to the group of synthetic polyesters, easily degradable by microorganisms [1]. It is used to produce implants and surgical sutures. It is also commonly used as a plasticizer of other plastics to increase their elasticity and biodegradability. Combined with starch, it is used to produce single-use dishes, which may later be composted. In the latest plastic manufacturing technologies attention is paid to creating surfaces which would have antibacterial properties and ensure their own sterility, as well as significantly reducingthe count of harmful microorganisms. For this purpose different biocidal substances are used: organic acids, enzymes, silver nanoparticles [2, 3]. To foil made from natural polymers, also grapefruit extracts, with high proanthocyanidins content (polymers made of catechin particles) are added, as well as flavons and flavanons, which demonstrate bactericidal, antiviral and antiparasitic properties [4]. PHMG is becoming increasingly popular due to its broad range of antimicrobial activity, but not due to the combination with the cytoplasm. Indeed, PHMG diffuses through the cellular membrane and binds to the cytoplasmic membrane forming a complex with the phospholipid molecules of the lipid bilayer, destabilizes the osmotic equilibrium and destructs cytoplasmic membrane, causing leakage of cell. It strongly reacts with nucleic acid, in both 
cases creatingionic bindings with monophosphate groups present in the bacterial cell and in the nucleic acid. PHMG used as an active ingredient in an antibacterial humidifier disinfectant were reported to cause harm to human health when inhaled, although physical contact with this material was known to present low toxicity to humans [5].

This research was aimed at determining the abundance of biofilm formation by E. coli and S. aureus on the surface of polycaprolactone with polyhexamethylene guanidine derivatives. Biocidal substances effect the enzymatic activity of this bacteria. Hence, the aim of the study was also to determine the effect of PHMG derivatives on the activity of extracellular hydrolases and intracellular dehydrogenases.

\section{Materials and Methods}

\section{Preparation of Composites}

For the production of the composites were used biodegradable PCL polymer and the three bactericidal PHMG derivatives with organic anions: sulfanilic acid salt, stearate, and granular polyethylene wax. All composites were from the Institute for Engineering of Polymer Materials and Dyes, Poland. The mixture of PCL and additional ingredients was prepared with the use of a co-rotating twin-screw extruder type BTSK 20 (Bühler, Germany) with the screw diameter of $20 \mathrm{~mm}$ and $\mathrm{L} / \mathrm{D}=40$, equipped with a segmented plasticizing system used to produce granulated composite. The composite was cold-granulated with cooling of the pomace in the air at the temperature of $25 \pm 3{ }^{\circ} \mathrm{C}$. The temperature of extrusion was $120^{\circ} \mathrm{C}$. The granulated product was used to produce flat films by means of a single-screw extruder type PlastiCorder PLV 151 (Brabender, Germany) equipped with a screw with diameter of $19.5 \mathrm{~mm}$ and $\mathrm{L} / \mathrm{D}=25$. The prepared samples had the following contents of PHMG derivatives: $0.0,0.2,0.6,1.0 \%(\mathrm{wt})$. The following symbols of the composites were used in the tests: A-PCL (PCL with the PHMG salt of sulfanilic acid), W-PCL (PCL with PHMG granular polyethylene wax), S-PCL (PCL with PHMG stearate). Control samples were pure PCL without PHMG derivatives. The tested PHMG derivatives are compounds of a copolymer produced by PHMG synthesis of an organic carrier according to Patent No: P.388062, 2009 [6].

\section{Test Strains}

Escherichia coli ATCC8739 and Staphylococcus aureus ATCC 6538P were used in the studies. The bacteria were cultured on PCA (Plate Count Agar, Biocorp, Poland) at $37^{\circ} \mathrm{C}$ for $24 \mathrm{~h}$. It was stored on the same medium at $4{ }^{\circ} \mathrm{C}$.

\section{Formation of Biofilm on the Surface of PCL with Introduced PHMG Derivatives}

Biofilm abundance was determined by spectrophotometry, using crystal violet staining [7]. A cultures of strains were prepared in flasks containing $50 \mathrm{ml}$ of liquid medium (nutrient broth, Biocorp). After $24 \mathrm{~h}$ of incubation at $37^{\circ} \mathrm{C}$ the biomass of cells was centrifuged and then suspended in peptone water. Density of the obtained cell suspension was $\mathrm{OD}=1.0$ according to McFarland scale $\left(1.5 \times 10^{8}\right.$ cells $\left./ \mathrm{ml}\right)$. This suspension was used in further determinations. For this purpose $0.2 \mathrm{ml}$ of the earlier prepared bacterial suspension and sterile pieces of the tested film $(5 / 5 \mathrm{~cm})$ were introduced onto sterile pans containing $20 \mathrm{ml}$ of nutrient broth. The film was sterilized with $70 \%$ ethanol and dried with sterile blotting paper. The bacterial suspension with the pieces of film were incubated for $48 \mathrm{~h}$ at $35^{\circ} \mathrm{C}$. During incubation, the cells first underwent adhesion and then, under favourable conditions, formed a more or less abundant biofilm on the surface of the tested material. After incubation, the pieces of film were taken from the pan, washed with distilled water in order to remove the cells not bound to the surface and then dried at room temperature. Afterwards the film was covered with $1 \%$ solution of crystal violet which bound to the biofilm biomass. The quantity of the bound violet is directly proportional to the volume of the formed biofilm. After $45 \mathrm{~min}$ the film was washed with distilled water in order to remove the unbound violet and dried once more at room temperature. The film with the biofilm was cut into sections of $0.5 / 1.5 \mathrm{~cm}$ and introduced into test tubes containing 96\% ethyl alcohol in order to wash off the earlier bound violet. Absorbance of the obtained alcohol extract was measured inthe spectrophotometer at wavelength $595 \mathrm{~nm}$. The control sample was prepared in the same way as the test, but the bacterial suspension was not introduced onto the medium. The determination was repeated triplicate. In order to evaluate the viability of biofilm forming bacteria, microorganisms retained on the filter surface were subjected to viability staining, using a diagnostic LIVE/DEAD set (Invitrogen) [8]. Fragments of the film $\left(1 \mathrm{~cm}^{2}\right.$ from each film) covered with the aqueous solutions of dyes of LIVE/DEAD (R) BacLight (TM) Bacterial Viability Kit were incubated for $15 \mathrm{~min}$ in the dark at room temperature. After the excess dye was removed, the samples were placed on microscope slides and viewed under oil immersion at $\times 1000$ magnification using Nikon H550S epifluorescence microscope with the appropriate filter set (470-490-nm excitation filter, 520-nm barrier filter). For each fragment 20-40 fields of view were evaluated (depending on how evenly the microorganisms were distributed). Color micrographs were taken with digital image processor (Olympus XC50) 
using the software package (CellB v. 3.1.). Viable cells were fluorescent green while non-viable cells were fluorescent red.

\section{Determination of the Effect of the PHMG Derivatives Introduced into PCL on Hydrolases Activity}

Escherichia coli and S. aureus were prepared in flasks containing $50 \mathrm{ml}$ of liquid medium (nutrient broth). After $24 \mathrm{~h}$ of incubation at $37^{\circ} \mathrm{C}$ the cultures were centrifuged at the speed of $10,000 \mathrm{rpm}$ to separate the cells from the postculture liquid $\left(+4^{\circ} \mathrm{C}\right)$. The obtained post-culture liquid containing hydrolases were used in further tests. The film $(5 \times 5 \mathrm{~cm})$ with $3 \mathrm{ml}$ of the obtained post-culture liquid was placed on sterile Petri plates. Everything was covered with another piece of film $(4.5 \times 4.5 \mathrm{~cm})$. The samples were preincubated for $1 \mathrm{~h}$ at $4{ }^{\circ} \mathrm{C}$. Then the post-culture liquid was collected from the tested film and put into Eppendorf test tubes. The activity of hydrolases after contact with the film was determined with the use of fluorscein diacetate by the Adam and Duncan method [9]. Concentration of the fluorescein released under the influence of hydrolases within $1 \mathrm{~h}$, at $30^{\circ} \mathrm{C}$ was measured by means of HITACHI F-2500 spectrofluorimeter at excitation wavelength $480 \mathrm{~nm}$ and emission wavelength $505 \mathrm{~nm}$. The control was film without the biocidal substance. The determination was done in triplicate.

\section{Determination of the Effect of the PHMG Derivatives Introduced into PCL on Dehydrogenases Activity}

A TTC test was used to determine dehydrogenase activity. We prepared a bacterial suspension with optical density $\mathrm{OD}=2$ according to $\mathrm{McF}$ arland scale $\left(6 \times 10^{8} \mathrm{cell} / \mathrm{ml}\right)$. Then pieces of film $(5 \times 5 \mathrm{~cm})$ with $3 \mathrm{ml}$ of the reaction mixture consisting of: bacterial suspension $(1 \mathrm{ml})$, Tris $\mathrm{HCl}$ buffer $\mathrm{pH}=8.4(1 \mathrm{ml}), 2 \%$ glucose solution $(0.4 \mathrm{ml}), 0.4 \%$ triphenyltetrazolium chloride (TTC) solution $(0.4 \mathrm{ml})$, sodium sulphate $0.36 \%(0.2 \mathrm{ml})$, were introduced onto sterile Petri plates. Everything was covered with another piece of film $(4.5 \times 4.5 \mathrm{~cm})$ and pre-incubated at $4{ }^{\circ} \mathrm{C}$ for $2 \mathrm{~h}$. Afterwards, the plates were moved to $37{ }^{\circ} \mathrm{C}$ and incubated for $24 \mathrm{~h}$. Triphenyltetrazolium chloride was reduced to triphenylformazan (TF). The concentration of TF was determined according to a standard curve using the Hitachi U1900 spectrophotometer. The determination was done in triplicate.

\section{Statistical Analysis}

The some results were analysed statistically. The twofactor analysis of variance ANOVA was used to enable comparison of the two independent factors: concentrations of PHMG and PHMG derivative.

\section{Results and Discussion}

\section{The Effect of PHMG Derivatives Introduced in PCL on Biofilm Formation}

E. coli and S. aureus formed biofilm on the surface of PCL containing PHMG derivatives. Biofilm-forming bacteria had high viability on PCL without PHMG. Abundance of the $E$. coli biofilm was decreased on the surface of PCL with PHMG granular polyethylene wax and PHMG salt of sulfanilic acid, especially on the W-PCL composite with $1 \%$ of PHMG. The amount of biofilm on the surface S-PCL at a concentrations of 0.2 and $0.6 \%$ PHMG was higher than on surface PCL without PHMG. While the amount of biofilm on the S-PCL (1\%) was similar to the control (Fig. 2). The observed tendency indicate that higher content of PHMG stearate than $1 \%$ is required to impart S-PCL films pronounced antibiofilm activity. Analysis LIVE/DEAD (Fig. 1) showed that the number of live cells were lower than that of dead cells and may indicated inhibitory effect of PCL-PHMG stearate (1\%).

$S$. aureus formed a smaller amount of biofilm on the surface of PCL than E. coli. The amount of the S. aureus biofilm on the surface PCL without PHMG and on composite S-PCL at a concentration of $0.2 \%$ was similar. However, all PHMG at a concentration of $1 \%$ inhibited biofilm formation (Fig. 2).

Polycaprolactone is used to produce, for instance, catheters. Catheters, as biomedical devices, are exposed to biofilm formation caused by pathological bacterial strains, including S. aureus or Salmonella typhimurium, which results in post-operative infections. From the medical point of view, interest in bacterial biofilm is justified by the difficulty in treating related infections [10]. The abundance of the biofilm formed on this type of materials was studied by Stickler et al. [11]. They assessed the ability to create a biofilm on the surface of a polycaprolactone-coated catheter using a Proteus mirabilis strain. In their study, they considered environmental $\mathrm{pH}$ which determined bacterial growth. On the basis of the data obtained they found that the most favourable conditions for the growth of bacterial biofilm are at $\mathrm{pH}$ over 8.2. Our research results showed that $S$. aureus formed less biofilm than $E$. coli. Research by Zhou et al. [12] indicates that low PHMG concentrations only damaged the external structures of bacterial cell membrane. Das et al. [13] determined the ability of E. coli and $S$. aureus to form biofilm on polymers with incorporated polyhexamethylene biguanide in the presence of acetic acid. Their research demonstrated that PHMG inhibits 
Fig. 1 Biofilm formation of Escherichia coli (a) and Staphylococcus aureus (b) on surface of PCL with 1\% PHMG derivatives by using the LIVE/ DEAD method. The live cells are green, dead cells are red (a) Escherichia coli

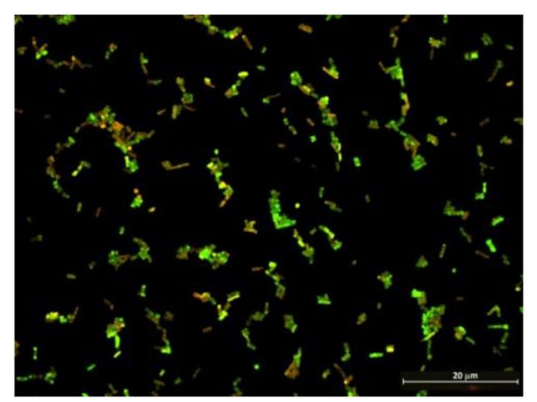

(b) Staphylococcus aureus

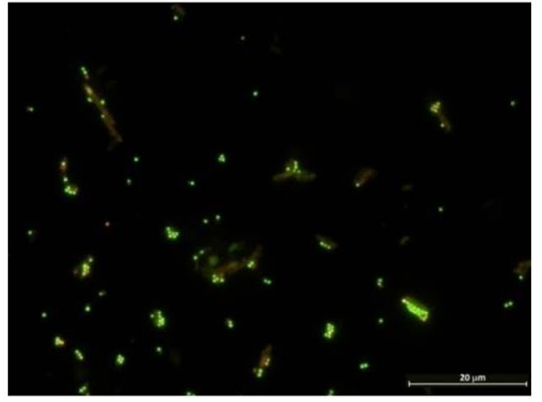

PCL without PHMG (control)
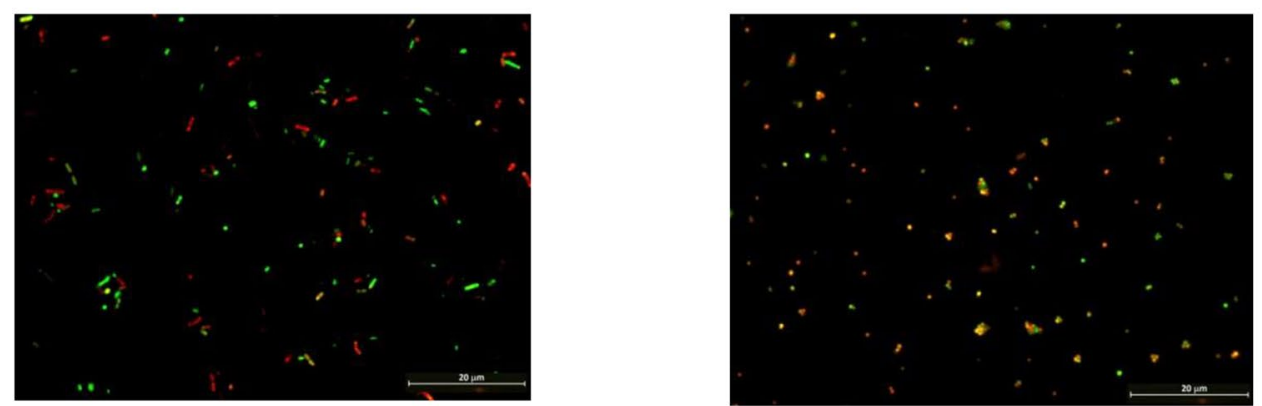

PCL with PHMG stearate
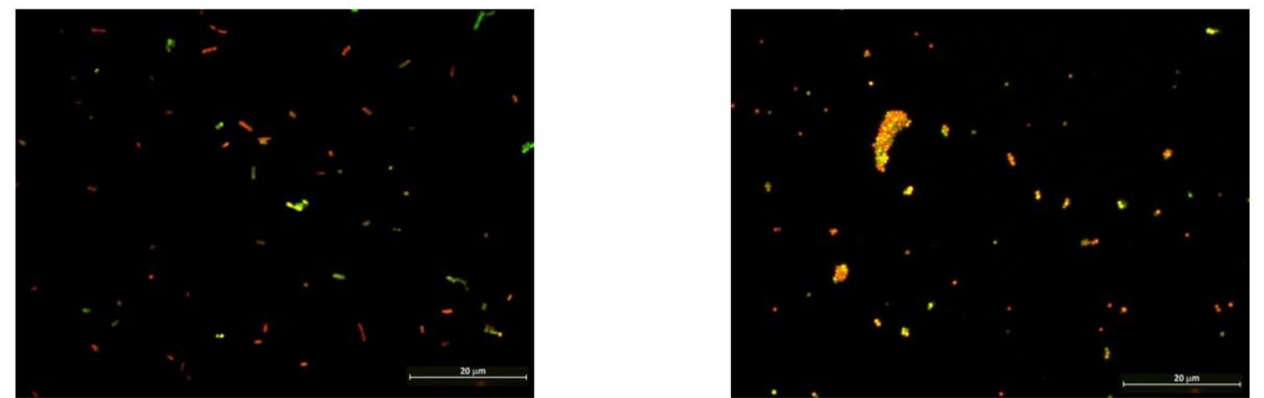

PCL with PHMG granular polyethylene wax
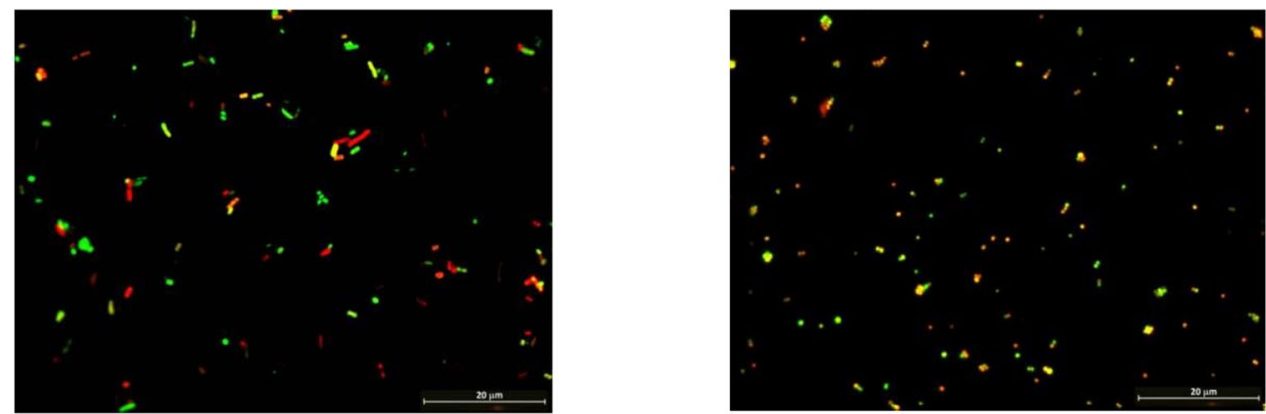

PCL with PHMG salt of sulfanilic acid

biofilm formation and reduces bacterial cells adhesion to polymer surfaces, which is beneficial in packaging and medical industries. On the other, the presence of biocide may reduce polymer biodegradation [14, 15]. Woolnough et al. [16] observed distinct biofilm on the surface of polylactide and polyhydroxybutyrate without incorporated biocidal substance. Due to that fact, within 50 days the foils lost $50 \%$ of their initial mass. Verstraeten et al. [17] reported that biofilm formation on polymer materials made of polylactide may be associated with co-operation between microbial cells. Their research revealed a strong affinity of Proteus mirabilis, Bacillus subtilis, E. coli and Salmonella enterica bacteria to biomaterials, and a considerable ability to inhabit them. Similar observations were made by Lefevre 

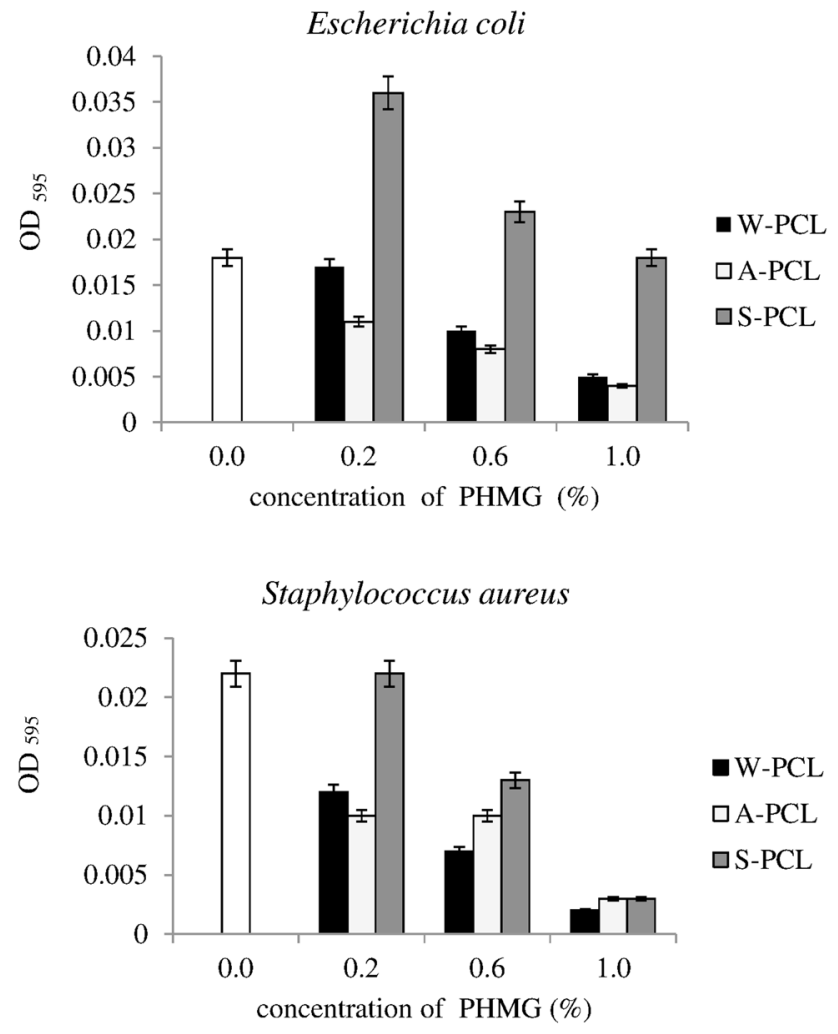

Fig. 2 The effect of PHMG derivatives introduced into PCL on biofilm formation (W-PCL granular polyethylene wax, A-PCL salt of sulfanilic acid, S-PCL stearate). Vertical bars represent standard error $(n=3)$

et al. [18] whose results indicate a high potential for biofilm formation on polymer surfaces.

Microbial biofilms are challenging to control using the available biocides. The main challenges are that the localized concentration of biofilm formers are covered by protective polymers and produce extracellular enzymes that can hinder biocidal activity, causing the failure of biocides to reach colonies in the deep layers, which are less susceptible due to the diluted doses that reach them and thus survive. The pathogens resist by forming biofilms, undergoing surface permeability changes, activating efflux pumps to remove biocides within the bacterial cell, inactivating the biocides' targeting ability using enzymes produced in response to the biocides applied and developing alternatives to the target sites of the biocide [19].

The effect of PHMG derivatives introduced into PCL on extracellular hydrolases and intracellular dehydrogenases activity.

PHMG derivatives introduced into PCL slightly affected hydrolases activity in $E$. coli at a concentrations of 0.2 and $0.6 \%$. S-PCL composite stimulated enzymes activity, but the values were not statistically significant (Table 1). However, PHMG granular polyethylene wax
Table 1 Two-way ANOVA comparing influence of PHMG derivatives introduced into PCL and concentration of PHMG on enzymatic activities

\begin{tabular}{|c|c|c|c|c|c|}
\hline \multirow[t]{2}{*}{ Enzymes } & \multirow[t]{2}{*}{ Test strains } & \multicolumn{2}{|c|}{$\begin{array}{l}\text { PHMG } \\
\text { derivatives }\end{array}$} & \multicolumn{2}{|c|}{$\begin{array}{l}\text { Concen- } \\
\text { tration of } \\
\text { PHMG }\end{array}$} \\
\hline & & $\mathrm{F}$ & $p$ & $\mathrm{~F}$ & $p$ \\
\hline Hydrolases & Escherichia coli & 3.2 & 0.121 & 0.3 & 0.725 \\
\hline Dehydrogenases & & 12.1 & 0.000 & 65.0 & 0.000 \\
\hline Hydrolases & Staphylococcus aureus & 12.1 & 0.000 & 8.2 & 0.000 \\
\hline Dehydrogenases & & 46.0 & 0.000 & 33.6 & 0.000 \\
\hline
\end{tabular}

$F$ among-groups variance/within-groups variance, $p$ significance

and PHMG salt of sulfanilic acid at a concentration of $1 \%$ inhibited hydrolases activity (Fig. 3). All PHMG derivatives inhibited the activity of $S$. aureus hydrolases proportionately to concentration. According to Fig. 3, W-PCL most strongly inhibited hydrolases activity in this bacterial strain.

All PHMG derivatives at studied concentration significantly inhibited dehydrogenases activity in $E$. coli, but
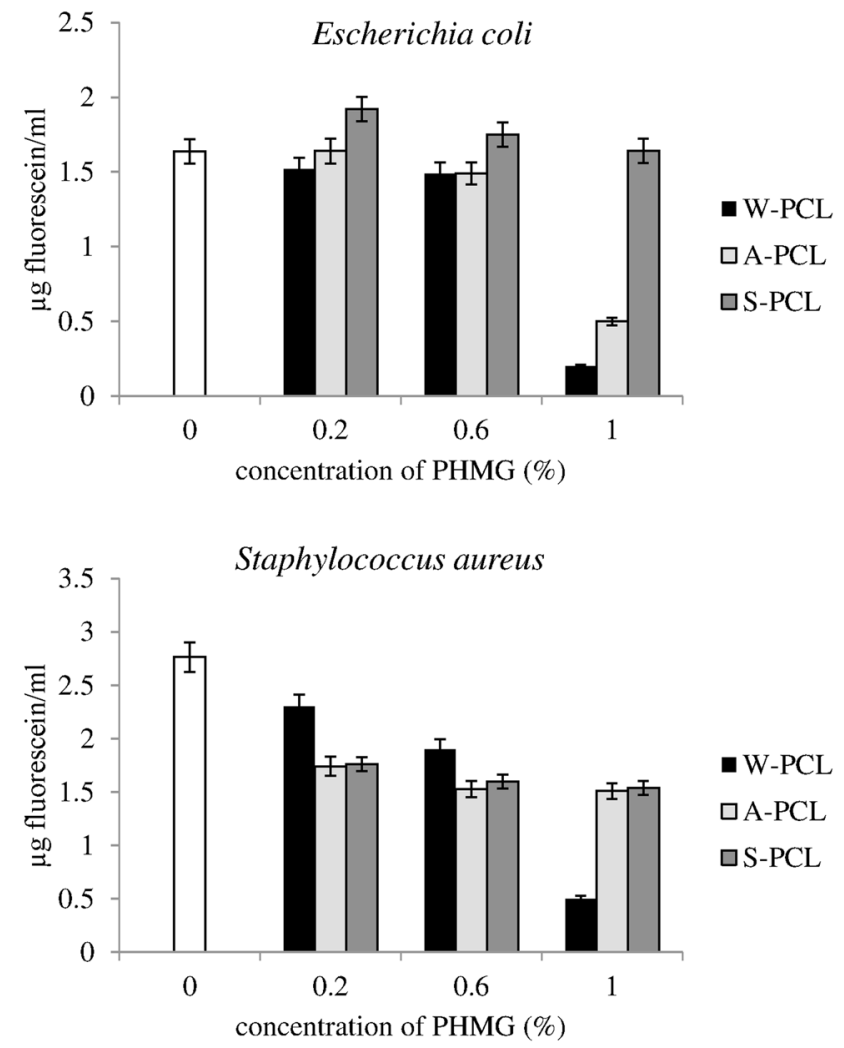

Fig. 3 The effect of PHMG derivatives introduced into PCL on hydrolase activity (W-PCL granular polyethylene wax, A-PCL salt of sulfanilic acid, S-PCL stearate). Vertical bars represent standard error $(n=3)$ 

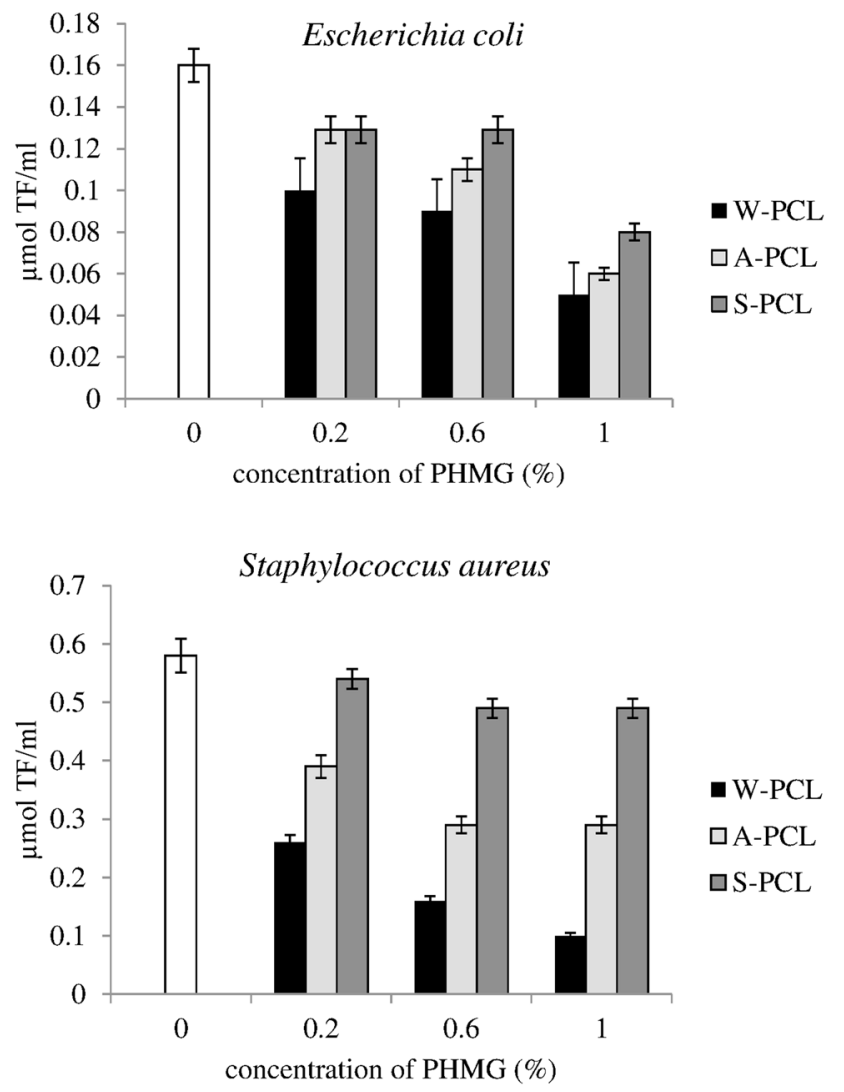

Fig. 4 The effect of PHMG derivatives introduced into PCL on dehydrogenase activity (W-PCL granular polyethylene wax, A-PCL salt of sulfanilic acid, S-PCL stearate). Vertical bars represent standard error $(n=3)$

W-PCL had a strongest inhibitory effect (Table 1; Fig. 4). Similarly, PHMG derivatives had a stronger inhibitory effect on dehydrogenases activity in S. aureus (Fig. 4). According to this figure, A-PCL inhibited dehydrogenases activity on $50 \%$, whereas W-PCL inhibited the activity on at least $80 \%$. S-PCL showed poor inhibitory activity.

In packaging industry, biodegradable polymers are often indirect contact with food products, where pathogenic bacterial con-tamination is one of the major issues. An ideal material for food packaging should therefore not only be biodegradable, but also possess an antimicrobial activity [20]. Biocides introduced into polymers can interact differently microbial cells. Biocides initially react with microorganisms on the surface of the cell. Therefore, the bacterial cell envelope considerably affects the course of this interaction, and subsequent penetration of the biocidal agent. Gram-negative bacteria are usually less prone to the effects of biocides than Gram-positive ones, as their cellular walls constitute a stronger barrier.

Antimicrobials fight bacteria through a variety of mechanisms, including damaging or inhibiting the synthesis of bacterial cell walls and affecting bacterial DNA or RNA, proteins or metabolic pathways [19]. PHMG, particularly at higher concentrations, can affect the bacterial cell membrane damage. Our research on LIVE / DEAD showed that the film PHMG at highest concentration (1\%) appeared are numerous dead cells associated with damage to the cell membrane. Biocides primarily cause changes in the permeability of the surface structures of bacteria, their degradation, and they inhibit the activity of bacterial enzymatic systems, which results in death of the bacteria [21]. Most AMMs (anti-microbial macromolecules) including PHMG have the charge and hydrophobicity moieties as anti-microbial peptides [22], and many researchers speculate that AMMs act by disruptive interaction on the lipid interface membrane as anti-microbial peptides, but there was a lack of experimental evidences on membrane disruption and their biological mechanism [22, 23]. According to Zhou et al. [12] and Linyan et al. [24] the biocidal activity of PHMG may be related to its ability to damage the cell membrane. Most probably, PHMG first damages the outer membrane, and then higher concentrations result in damage to of the cell wall and cytoplasmic membrane [12]. Walczak et al. [25] showed that PLA with PHMG derivatives did not inhibit the activity of extracellular hydrolytic enzymes, which means that the introduction of PHMG derivatives into PLA will not reduce its enzymatic biodegradation significantly. However PHMG derivatives inhibited the activity of cellular dehydrogenases, which may be related to PHMG mode of action, relying primarily on damaging the cell membrane.

The mechanism of action of PCL/PHMG composites could be contact-active rather than biocide releasing due to the low water solubility of PHMG salts. Therefore, some composites (S-PCL) even at high concentrations PHMG do not significantly affect enzyme activity. This allows the process of biodegradation of such polymers is not disturbed. According to Siedenbiedel et al. [26] antimicrobial surfaces are usually designed by impregnation of materials with biocides that are released into the surroundings whereupon microbes are killed. Antimicrobial polymers are the up and coming new class of disinfectants, which can be used even as an alternative to antibiotics in some cases. Interestingly, antimicrobial polymers can be tethered to surfaces without losing their biological activity, which enables the design of surfaces that kill microbes without releasing biocides. Contact-active surfaces are often considered to be self-deactivating, because killed microbes may adhere to the active layer and new approaching microbes can adhere and proliferate on these corpses. An improvement to such surfaces would be a material that kills microbes and repels the dead cells simultaneously [26]. Additionally, almost every material can be degraded by microbial biofilms [27]. 
PHMG could have affect different metabolic pathways and cell elements including hydrolytic enzymes secreted to hydrolyze the polymer. Impaired activity of these enzymes can lead to lower hydrolysis efficiency, which, in turn, impairs biodegradability of the composite [25]. One of the most important factors influencing PCL biodegradation are microorganisms which produce different types of PCL hydrolases; esterases and lipases [28]. S. aureus and E. coli are model strains for determination of biocidal properties [29]. No significant inhibition of the hydrolytic activity of E. coli and a slight inhibition of $S$. aureus hydrolases indicates that the presence PHMG derivative does not significantly affect the biodegradability of these polymers. Only in the highest concentration of derivatives can significantly lower the degradability.

\section{Conclusion}

Three derivatives of polymeric biocide PHMG: stearate, sulfanilate and PHMG granular polyethylene wax have been used to impart antibiofilm activity to biodegradable polymer PCL. The PCL containing PHMG granular polyethylene wax and sulfanilate (at concentration of $0.6-1 \%$ ) strongest inhibited E. coli and S. aureus biofilm. PHMG derivatives introduced into PCL were found to slightly affect hydrolases activity in both $E$. coli and $S$. aureus at a concentration of 0.2 and $0.6 \%$. It was also found that dehydrogenases activity was inhibited by PCL films containing PHMG derivatives. PCL containing 1\% of PHMG sulfanilate strongest inhibited hydrolases activity, whereas PCL modified with $1 \%$ of PHMG granular polyethylene wax showed the highest inhibitory effect on the activity of both enzymes. The introduction of PHMG derivatives into the PCL can be an interesting alternative to existing packaging materials and biomaterials. The composites produced from PCL and this PHMG derivative can be used in many areas to reduce the growth of microorganisms. At the same time, the investigated some PCL composites strong did not inhibit extracellular hydrolytic enzymes activity, which means that the introduction of PHMG derivatives into PCL will not reduce its enzymatic biodegradation significantly.

Acknowledgements The project was funded by the National Science Centre of Poland, decision No. UMO-2011/01/B/NZ9/00230.

Open Access This article is distributed under the terms of the Creative Commons Attribution 4.0 International License (http:// creativecommons.org/licenses/by/4.0/), which permits unrestricted use, distribution, and reproduction in any medium, provided you give appropriate credit to the original author(s) and the source, provide a link to the Creative Commons license, and indicate if changes were made.

\section{References}

1. Nishida H, Tokiwa Y (1993) J Environ Polym Degrad 1:227

2. Appendini P, Hotchkiss JH (2002) Innovative Food Sci Emerg Technol 13:113

3. Burkowska-But A, Sionkowski G, Walczak M (2014) J Environ Sci 26:542

4. Malinowska-Pańczyk E, Sztuka K, Kołodziejska I (2010) Polymers 9:625

5. Hwang HJ, Nam J, Yang SIK, Kwon JH, Oh HB (2013) Bull Korean Chem Soc 34:1708

6. Królikowski B, Szuster L, Wyrębska $Ł$ (2009) The method of obtaining the bioactive product. Polish Patent. Aplication Number P.388062

7. O'Toole GA, Kolter R (1998) Mol Microbiol 28:449

8. Davies Ch (1991) Lett Appl Microbiol 13:58

9. Adam G, Duncan (2001) Soil Biol Biochem 33:943

10. Sbordone L, Bortolaia C (2003) Clin Oral Investig 7:181

11. Stickler DJ, Lear JC, Morris NS, Macleod SM, Downer A, Cadd DH, Feast WJ (2006) J Appl Microbiol 100:1028

12. Zhou ZX, Wie DF, Guan Y, Zheng AN, Zhong JJ (2010) J Appl Microbiol 108:89

13. Das JR, Bhakoo M, Jonas MU, Gilbert P (1989) J Appl Microbiol 84:852

14. Chłopek J, Morawska-Chochół A, Szaraniec B (2010) J Achiev Mater Manufact Eng 43:72

15. Rasal RM, Janorkar A, Hirt DE (2010) Progr Polymer Sci 35:338

16. Woolnough CA, Yee LH, Charlton T, Foster LJ (2010) Polymer Intern 59:658

17. Verstraeten N, Braeken K, Debkumari B, Fauvart M, Fransaer J (2008) Trends Microbiol 16:496-

18. Lefèvre C, Tidjani A, Wauven CV, David C (2002) J Appl Polym Sci 83:1334

19. Ashraf MA, Ullah S, Ahmad I, Qureshi AK, Balkhairf KS, Rehmang MA (2014) J Sci Food Agric 94:388

20. Wojciechowski K, Kladzińska E (2015) Colloids Surf A Physicochem Eng Aspects 483:204

21. Reuter G (1994) Fleiswirtschaft 74:808

22. Gabriel GJ, Som A, Madkou AE, Eren T, Tew GN (2007) Mater Sci Eng R Rep 57:28

23. Gilbert P, Moore LE (2005) J Appl Microbiol 99:703

24. Linyan FW, Jing L, Yueming J, Xuewu D (2011) Postharvest Biol Technol 61:160

25. Walczak M, Richert A, Burkowska-But A (2014) J Ind Microbiol Biotechnol 41:1719

26. Siedenbiedel F, Tiller JC (2012) Polymers 4:46

27. Macedo MF, Miller AZ, Dionisio A, Saiz-Jimenez C (2009) Microbiology 155:3476

28. Tokiwa Y, Suzuki T (1997) Nature 270:76

29. ISO 22196 (2011) Plastics measurement of antibacterial activity on plastics surfaces 